\title{
A OBSOLESCÊNCIA NA PRODUÇÃO DE MERCADORIAS: UM IMPERATIVO MATERIAL DO DESENVOLVIMENTO DO SISTEMA DO CAPITAL
}

\author{
LA OBSOLESCENCIA EN LA PRODUCCIÓN DE MERCANCÍAS: \\ UN IMPERATIVO MATERIAL DEL DESARROLLO DEL SISTEMA DE
}

\section{THE OBSOLESCENCE IN THE PRODUCTION OF GOODS: A MATERIAL IMPERATIVE FOR THE DEVELOPMENT OF THE CAPITAL SYSTEM}

DOI: $10.22481 /$ rbba.v10i01.8775

Mailton Rocha Pereira

Universidade Estadual do Sudoeste da Bahia ID Lattes: http://lattes.cnpq.br/2898862168561998 ORCID: https://orcid.org/0000-0002-7837-1800 Endereço eletrônico: mailtonrp@yahoo.com.br

José Rubens Mascarenhas de Almeida Universidade Estadual do Sudoeste da Bahia ID Lattes: http://lattes.cnpq.br/3920900756591288

ORCID: https://orcid.org/0000-0002-0232-5461 Endereço eletrônico: rubens.mascarenhas@uesb.edu.br

\section{RESUMO}

Este artigo tem o escopo de refletir acerca da obsolescência de mercadorias como um processo atrelado ao desenvolvimento das forças produtivas. Nesse sentido, busca-se compreendê-la à luz dos desdobramentos históricos da subordinação das necessidades humanas à reprodução do valor-de-troca. Apresenta ainda a obsolescência planejada no século XX, caracterizada pela redução da vida útil dos produtos de forma deliberada no âmbito da produção como um expediente resultante desse 


\title{
A OBSOLESCÊNCIA NA PRODUÇÃO DE MERCADORIAS: UM IMPERATIVO MATERIAL DO DESENVOLVIMENTO DO SISTEMA DO \\ CAPITAL
}

processo histórico que, em tempos de crise estrutural, emerge como artifício do capital para deslocar a contradição entre produção e consumo.

Palavras-chave: Obsolescência de mercadorias; Obsolescência planejada; Produção; Consumo.

\section{RESUMEN}

Este artículo pretende reflexionar sobre la obsolescencia de los bienes como um proceso ligado al desarrollo de las fuerzas productivas. En este sentido, busca entenderlo a la luz del despliegue histórico de la subordinación de las necesidades humanas a la reproducción del valor de cambio. También presenta la obsolescencia planificada em el siglo XX, caracterizada por la reducción de la vida útil de los productos de forma deliberada dentro de la producción como un expediente resultante de este proceso histórico que, em tiempos de crisis estructural, emerge como un artificio del capital para desplazar la contradicción entre producción y consumo.

Palabras clave: Obsolescencia de los bienes; Obsolescencia planificada; Producción; Consumo.

\begin{abstract}
This article aims to reflect on the obsolescence of goods as a process linked to the development of the productive forces. In this sense, it seeks to understand it in the light of the historical unfolding of the subordination of human needs to the reproduction of exchange value. It also presents the planned obsolescence in the twentieth century, characterized by the reduction of the useful life of products in a deliberate way in the context of production as an expedient resulting from this historical process that, in times of structural crisis, emerges as an artifice of capital to displace the contradiction between production and consumption.
\end{abstract}

Keywords: Commodity obsolescence; Planned obsolescence; Production; Consumption.

\section{INTRODUÇÃO}

De forma geral, a obsolescência é compreendida como o envelhecimento precoce de mercadorias ou processos mediante ação deliberada dos agentes produtivos. O termo é 


\section{A OBSOLESCÊNCIA NA PRODUÇÃO DE MERCADORIAS: UM IMPERATIVO MATERIAL DO DESENVOLVIMENTO DO SISTEMA DO \\ CAPITAL}

empregado recorrentemente nas diversas áreas do conhecimento humano (filosófico, científico, senso comum etc.) para definir no campo tecnológico o processo intencional e deliberado da diminuição do tempo de vida útil dos produtos desde seu planejamento e produção nas fábricas capitalistas.

Esta obsolescência denominada planejada/programada (doravante OP) manifestou-se no primeiro quartel do século XX, surgindo como antídoto forjado no planejamento da produção e na racionalização da atividade das grandes corporações, cuja economia capitalista visava compor a demanda como forma de alavancar as vendas.

No entanto, o estudo da problemática da OP como um momento isolado na história atrelada à esfera do consumo leva a importante questão da orientação das práticas produtivas para o terreno da garantia da demanda efetiva. O que permitiu sua vinculação a uma discussão que limitou a resolução dos problemas da sociedade ao avanço material-produtivo (supostamente garantido pela ciência, eficiência técnica e acumulação do capital ${ }^{i}$ ), tendo o consumo de massa como sua principal justificativa.

Neste sentido, assumir o consumo de massa - sustentado pela OP - como representação de algum estágio de emancipação humana é algo que deve ser analisado criticamente. Para tanto, será válido investigar a OP no contexto daquela obsolescência atrelada ao desenvolvimento das forças produtivas, a qual se caracteriza pela substituição dos meios de produção no processo de inovação resultante do empenho dos capitalistas em extrair a maisvalia relativa, relacionada às leis coercitivas da concorrência e à luta de classes.

Assim, pensamos ser possível apresentar elementos para um necessário estudo da obsolescência em geral (caracterizada historicamente pela quantificação de mercadorias e aceleração do giro destas na esfera do consumo) considerando a OP do século XX como um momento resultante e subordinado a esse processo.

\section{A SEPARAÇÃO ENTRE PRODUÇÃO E CONSUMO COMO CONDIÇÃO DA EXISTÊNCIA DA OBSOLESCÊNCIA DE MERCADORIAS EM GERAL}

Para além do caráter conjuntural e específico da OP no século XX, acreditamos ser necessária uma investigação dos viabilizadores históricos da obsolescência de mercadorias em geral, para melhor entender a OP do século XX e seus desdobramentos na manutenção da rotação do capital. 


\section{A OBSOLESCÊNCIA NA PRODUÇÃO DE MERCADORIAS: UM IMPERATIVO MATERIAL DO DESENVOLVIMENTO DO SISTEMA DO \\ CAPITAL}

Para traçar essa aproximação, recorremos à análise de Marx, em O Capital, acerca do desenvolvimento/constituição da forma mercadoria, além das suas consequências na esfera da

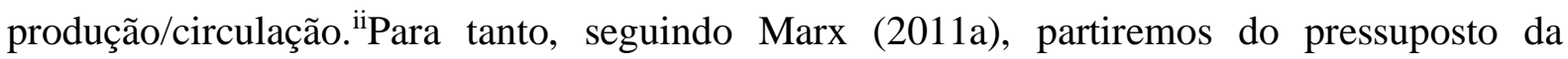
produção de mercadorias (o que implica em produtos voltados para o mercado, como valor-detroca). Tal fato não limita ou anula nesses produtos a determinação de que se constituam também como valor-de-uso, pois o mesmo autor afirma que o produto do trabalho, independente da forma que assume em determinada formação social, resulta de uma atividade metabólica entre o homem e natureza, cuja função primordial, antes de tudo, consiste em suprir as necessidades humanas.

Por outro lado, Marx (2011a) explica a determinação que assume o valor-de-troca enquanto finalidade no processo de trabalho capitalista. Assim, entender o processo de trabalho capitalista como dominado pelo valor-de-troca é crucial para nossa análise, porque nos permite perceber que as mercadorias advindas deste processo são produzidas, em primeiro lugar, com o propósito de reproduzir capital.

Para um esforço inicial no sentido de se pensar a obsolescência de mercadorias (ou avanço das forças produtivas) como resultante da necessidade de valorização do capital, partimos da explicação marxiana sobre a forma e desenvolvimento da circulação do dinheiro como capital - processo histórico que desencadeou a retirada do valor-de-uso como finalidade da produção humana. Para Marx (2011a), a circulação de capital se origina na forma simples, o que teria ocorrido em períodos históricos anteriores ao dominado pelo capital. Nela, os trabalhadores privados intercambiavam seus produtos entre si reciprocamente como valoresde-uso. O objetivo final era a satisfação das necessidades na esfera do consumo, funcionado o dinheiro apenas como mediador dessa relação.

Neste tipo de circulação, o desenvolvimento das forças produtivas (no qual já se percebe implícito algum tipo de obsolescência) e sua correspondente produção de excedente ${ }^{\mathrm{iii}}$ não podem existir sob a forma da subutilização e do desperdício generalizado de recursos, pois "a organização e a divisão do trabalho tinham que ser fundamentalmente diferentes em sociedades nas quais o valor-de-uso e a necessidade exerciam as funções reguladoras decisivas." (MÉSZÁROS, 2011, p. 606). Portanto, aqui não estamos pensando na OP em sua forma típica ligada à intencionalidade premeditada, mas na obsolescência em geral.

Na sucessão de etapas (venda e compra) da circulação simples, Marx (2011a) identifica uma inversão histórica marcada pela obliteração da determinação exercida pelo valor-de-uso 


\section{A OBSOLESCÊNCIA NA PRODUÇÃO DE MERCADORIAS: UM IMPERATIVO MATERIAL DO DESENVOLVIMENTO DO SISTEMA DO \\ CAPITAL}

nas relações de troca, na qual a meta final é o dinheiro (valor-de-troca). Na forma de circulação de capital, a inversão na sucessão das etapas modifica a posição dos agentes da troca e subordina o valor-de-uso dos produtos, estabelecendo-se o capital como controlador do metabolismo social e abrindo espaço à compra da força de trabalho. De acordo com Marx (2011a), a compra da força de trabalho inaugura a época do Capitalismo. Assim, o processo de trabalho passa a ser controlado pelo capitalista que, como possuidor do dinheiro, compra todas as mercadorias necessárias, os meios de produção em geral (matérias-primas, máquinas e a força de trabalho), promovendo a produção de valores-de-uso apenas como veículos dos valores-de-troca (mercadorias). Com o objetivo de retirar da circulação mais dinheiro do que a soma dos valores das mercadorias que comprou, é que ele se dispõe a investir no processo de produção. Nesse sentido, afirma Marx (2011a, p. 220):

[...] além de produzir um valor-de-uso, quer produzir mercadoria; além de valor-de-uso, valor, e não só valor, mas também valor excedente (mais-valia). [...]. Sendo a própria mercadoria unidade de valor-de-uso e valor, o processo de produzi-la tem de ser um processo de trabalho ou um processo de produzir valor-de-uso e, ao mesmo tempo, um processo de produzir valor.

Assim, a produção de mercadorias como unidade de processo de trabalho e de valorização pressupõe essa subordinação ao valor-de-troca, como necessidade interna do esquema de reprodução do capital, cujo objetivo final situa-se na produção de valor excedente, denominado mais-valia. Salientamos ainda que os produtos, ainda que envoltos pela forma mercadoria nesta relação, continuam a possuir valor-de-uso para seus não-proprietários; porém, dentro de uma relação de subordinação ao valor-de-troca. Assim,

[...] a destroçada unidade de necessidade e produção [...] é "remendada", mesmo que de uma forma caracteristicamente perversa, de modo a se ajustar aos limites do processo metabólico do capital. O que agora conta como "necessidade" não é a necessidade humana dos produtores, mas os imperativos estruturais da própria valorização e reprodução do capital. (MÉSZÁROS, 2011, p. 628).

Podemos reconhecer que essa guinada histórica no modo de produzir/reproduzir da sociedade teve uma consequência no tempo de existência (tempo de vida útil ou taxa de utilização $^{\text {iv }}$ ) das mercadorias, haja vista que o capital passou a determinar o quê, como e em qual quantidade se deveria produzir, graças à disjunção empreendida entre produção e consumo. Mészáros (2011), ao criticar Charles Babbage, pensador do século XIX, a respeito 


\title{
A OBSOLESCÊNCIA NA PRODUÇÃO DE MERCADORIAS: UM IMPERATIVO MATERIAL DO DESENVOLVIMENTO DO SISTEMA DO \\ CAPITAL
}

da abordagem acerca das manifestações de não durabilidade de artigos manufaturados e práticas de obsoletização naquele período como fenômenos de meras "circunstâncias especiais", adverte que, devido ao "ponto vista da economia política” do autor,

\begin{abstract}
deve-se ignorar por completo o fato de que, em sua tendência geral, o modo capitalista de produção seja inimigo da durabilidade e que, portanto, no decorrer de seu desenvolvimento histórico, deve minar de toda maneira possível as práticas produtivas orientadas-para-a-durabilidade, inclusive solapando deliberadamente a qualidade. (MÉSZÁROS, 2011, p. 636).
\end{abstract}

Isto nos leva a considerar que, por via dessa inversão na finalidade da produção, impõese uma redefinição do sentido de "utilidade" e da "forma de uso" dos produtos já inclusa nesta fase de desenvolvimento sistêmico, além da citada queda na durabilidade como tendência. Sendo a "utilidade" um constructo histórico, dado que este termo esteja em consonância com as práticas produtivas de cada época sob o domínio do capital, a correspondência entre os tipos de bens pelos quais a sociedade vai produzir/reproduzir e as necessidades humanas (consumo) passa a ser forjada de acordo com os parâmetros impostos pela lógica da reprodução do valorde-troca.

Ainda merece menção a indicação de Mészáros de que, com a subversão da unidade entre necessidade e produção, o trabalhador sai do controle do processo produtivo. Assim,

[...] o trabalhador somente pode obter acesso a uma determinada classe e quantidade de valores de uso - correspondendo-a ou não às suas necessidades reais - enquanto o capital, com base na unidade reconstituída de necessidade (troca) e produção (reprodução), os legitima como viáveis e lucrativos no interior da estrutura da homogeneização corrente. Por essa via, o trabalhador internaliza as necessidades e os imperativos do capital como seus próprios, como inseparáveis da relação de troca e por isso aceita a imposição dos valores de uso capitalisticamente viáveis como se emanassem de suas próprias necessidades. (MÉSZÁROS, 2011, p. 628).

Por isso, o não-controle do trabalhador sobre o destino daquilo que será produzido pela sociedade é uma decorrência do domínio do capital sobre o processo de trabalho (subordinação do valor-de-uso ao valor-de-troca). Este acontecimento histórico abre espaço, dentre outros tão importantes quanto, para a disseminação da obsolescência de mercadorias, visto que o aumento da produtividade em conjunto com a ampliação do círculo de consumo deve ser buscado por meio da inovação (desenvolvimento das forças produtivas). Por outro lado, o trabalhador subordinado à engrenagem do processo de trabalho capitalista perde seu papel na mediação das 


\section{A OBSOLESCÊNCIA NA PRODUÇÃO DE MERCADORIAS: UM IMPERATIVO MATERIAL DO DESENVOLVIMENTO DO SISTEMA DO \\ CAPITAL}

práticas produtivas orientadas para a durabilidade que visa a utilização racional dos produtos do trabalho. Desta forma, transformam-se trabalhadores em consumidores, significando isto na atualidade como consumo e utilização em tempo mínimo.

\section{A OBSOLESCÊNCIA DE MERCADORIAS COMO DESDOBRAMENTO DA EXTRAÇÃO DA MAIS-VALIA RELATIVA}

Embora a extração da mais-valia absoluta no capitalismo tenha representado (e ainda representa) uma transformação brutal no modo de produção da sociedade sob o ponto de vista da forma, de acordo com Rosdolsky (2011), não há no capitalismo uma novidade histórica em relação às anteriores sociedades de classe - mecanismo pelo qual a classe dominante exerce a exploração do trabalho, uma vez que todas baseiam-se na apropriação do excedente produzido pelos trabalhadores.

No entanto, no capitalismo é predominante a quantificação de mercadorias em escala diferenciada em relação às formações sociais anteriores por existir uma pressão para a expansão dos sistemas de comércio e do círculo de necessidades. Tal quantificação está relacionada à forma típica de extração de mais-valia que marca o início da época dominada pelo capital, concretizada pela ampliação da jornada de trabalho. Momento em que, segundo Marx (2011a, p. 36), “[...] o capital se apossa do processo de trabalho na situação em que se encontra ou que lhe foi historicamente transmitida, limitando-se a prolongar a sua duração".

Rosdolsky (2011), por seu turno, adverte que na teoria marxiana somente a constatação da extração de mais-valia pelo prolongamento da jornada de trabalho não é suficiente para caracterizar a essência do modo de produção capitalista. Ela estaria relacionada à mais-valia relativa, na qual (ao contrário da absoluta) a jornada inteira de um dia de trabalho se torna gradativamente uma variável constante devido, principalmente, à relativa regulamentação do tempo da jornada de trabalho efetivada pela correlação de forças existentes entre capital e trabalho presente no início do desenvolvimento capitalista. Com a jornada de trabalho como variável constante, ocorre uma pressão para se comprimir o tempo de trabalho necessário (aquele correspondente ao requerido para se produzir as mercadorias necessárias à sobrevivência do trabalhador) com o intuito de prolongar o tempo de trabalho excedente do qual o capitalista se apropria gratuitamente. No entendimento de Marx (2011a, p. 363-4), 


\section{A OBSOLESCÊNCIA NA PRODUÇÃO DE MERCADORIAS: UM IMPERATIVO MATERIAL DO DESENVOLVIMENTO DO SISTEMA DO \\ CAPITAL}

A prolongação do trabalho excedente corresponderá à redução do trabalho necessário, ou parte do tempo de trabalho que o trabalhador até agora utilizava realmente em seu benefício transforma-se em tempo de trabalho para o capitalista. O que muda não é a duração da jornada de trabalho, mas seu modo de repartir-se em trabalho necessário e trabalho excedente.

Entender esta necessidade reprodutiva do capital é essencial para a compreensão do fenômeno da obsolescência, pois que essa se encontra intrinsecamente interconectada à jornada de trabalho à qual agrega tempo excedente, buscando garantir extração da mais-valia, reduzindo-se o tempo socialmente necessário para a produção de mercadoria. Daí, no extremo, o capital deve se empenhar em aumentar a produtividade do trabalho mediante a "alteração no instrumental ou no método de trabalho, ou em ambos ao mesmo tempo.” (MARX, 2011a, p. $365)$.

Desta forma, o capital volta-se sempre para o desenvolvimento das forças produtivas o que modifica o próprio modo de produção em todos os seus aspectos. Como consequência, desenvolve-se um processo de criação de necessidades para a composição da demanda por novos valores-de-uso (resultantes de inovação) o que, por sua vez, promove a obsolescência das mercadorias em todas as esferas da produção. Não por acaso na teoria marxiana, o sistema capitalista é caracterizado por uma tendência de expansão da esfera da circulação por meio da criação de novos ramos de atividades produtivas a fim de se manter a rotatividade de capital e com ela a mais-valia relativa. Sendo assim,

[...] a produção de valor excedente relativo, i.e., a produção de valor excedente fundada no aumento e no desenvolvimento de forças produtivas, requer a produção de novo consumo; requer que o círculo de consumo no interior da circulação se amplie tanto quanto antes se ampliou o círculo produtivo. Primeiro, ampliação quantitativa do consumo existente; segundo, criação de novas necessidades pela propagação das existentes em um círculo mais amplo; terceiro, produção de novas necessidades e descoberta e criação de novos valores de uso. (MARX, 2011, p. 540).

Assim, diante desse processo da inovação e do revolucionamento das forças produtivas, levados a cabo pela expansão do capital para se potencializar a demanda, o desenvolvimento da substituição acelerada dos produtos na esfera do consumo é encetado, reduzindo-se sua vida útil e/ou diminuindo-se seu tempo de uso. 


\section{A OBSOLESCÊNCIA NA PRODUÇÃO DE MERCADORIAS: UM IMPERATIVO MATERIAL DO DESENVOLVIMENTO DO SISTEMA DO \\ CAPITAL}

Com base nessas considerações, pensamos que a obsolescência (não acompanhada da adjetivação planejada ou programada) já se encontra presente na realização da mais-valia relativa pelo capital ao requerer a transformação dos meios técnicos e das formas de realização do trabalho que ocorre concomitante à expansão do círculo de consumo e necessidades - prova de que o fenômeno da obsolescência emana do processo de realização do capital (produção/circulação/consumo). Foi o que se objetivou com a expansão do círculo de consumo advinda do desenvolvimento da maquinaria na Revolução Industrial, fenômeno caracterizado principalmente pela inovação/invenção de novas máquinas enquanto meios de produção de capital, cujo objetivo consistia em aumentar a produtividade daqueles valores-de-uso já existentes e conhecidos pelos consumidores. Ainda no início desse processo, Marx apontava como a relação concorrencial nascente daquele momento impelia os capitalistas individuais a perseguirem a inovação das máquinas pela necessidade de barateio do preço das mercadorias. Dizia que "a máquina experimenta ainda, além do material, o desgaste moral. Perde valor-detroca, na medida em que se podem reproduzir mais barato máquinas da mesma construção ou fazer melhores máquinas que com ela concorram.” (MARX, 2011a, p. 462).

Apreendendo tal processo como positivo, por outro lado, ideólogos, como o economista Schumpeter, que trata tais práticas produtivas como "destruição criadora", destacavam e exaltavam as revoluções que modificam a técnica e que geram uma série de novas mercadorias para o consumo, sobretudo das massas, como estradas de ferro, automóveis, aparelhos domésticos etc., através de um processo evolutivo; pois, é sabido que

[...] (guerras, revoluções e assim por diante) produzem freqüentemente transformações industriais. [...] O impulso fundamental que põe e mantém em funcionamento a máquina capitalista procede dos novos bens de consumo, dos novos métodos de produção ou transporte, dos novos mercados e das novas formas de organização industrial criadas pela empresa capitalista. [...] Este processo de destruição criadora é básico para se entender o capitalismo. É dele que se constitui o capitalismo e a ele deve se adaptar toda a empresa capitalista para reviver (SCHUMPETER,1961, pp. 105 - 106).

Muito embora a argumentação de Schumpeter esteja correta em relação à manifestação do fenômeno da obsolescência sob o ponto de vista da natureza destrutivo-criadora ante as bases do capitalismo, este se equivoca ao desconsiderar a essência da obsolescência - essência presente na análise marxiana que o antecedeu - que vê tal fenômeno como constitutivo da 


\section{A OBSOLESCÊNCIA NA PRODUÇÃO DE MERCADORIAS: UM IMPERATIVO MATERIAL DO DESENVOLVIMENTO DO SISTEMA DO \\ CAPITAL}

necessidade de extração da mais-valia relativa pela exploração do tempo de trabalho excedente da sociedade. Schumpeter, substituindo a essência pela aparência, concebe como responsável pela destruição criadora o pressuposto empreendedorismo do capitalista individual. Nesse sentido, o critica Harvey (2012, p. 102), quando diz que o capitalismo “é por necessidade, tecnologicamente dinâmico, não por causa das míticas capacidades do empreendedor inovador (como Schumpeter viria a alegar), mas por causa das leis coercitivas da competição e das condições de luta de classes endêmicas no capitalismo".

De todo modo, a perspectiva ao se relacionar produtividade e quantificação capitalista a um momento de prosperidade deve ser avaliada em seu contexto histórico (início do desenvolvimento capitalista) no qual as práticas que viriam a tornar a obsolescência em uma tendência estavam apenas indicadas.

A tendência à disseminação da obsolescência nas práticas produtivas como consequência da necessidade da mais-valia relativa, constatada empiricamente ao nosso tempo, pôde ser observada e teorizada por Marx em seu tempo. Apesar de não utilizar o termo, Marx já indicava a existência do fenômeno em várias passagens de suas obras da juventude e n' $O$ Capital, ainda que seu contexto histórico restringisse a possibilidade de apreensão dos desdobramentos destrutivos daquilo que viria a ser conhecido por OP. Assim, na obra que escreveu juntamente com Engels, o Manifesto Comunista, os autores afirmam que na sociedade burguesa "dissolvem-se todas as relações sociais antigas e cristalizadas, com seu cortejo de concepções e de ideias secularmente veneradas; as relações que as substituem tornam-se antiquadas antes de se consolidarem. Tudo que é sólido e estável se desmancha no ar.” (MARX \& ENGELS, 2010, p. 43). A citação indica a apreensão da obsolescência como uma tendência própria da sociedade capitalista, incidindo-se em vários aspectos da vida humana. A leitura desta passagem por Berman (1986, p. 97) é singular. Para ele,

como Marx vê, tudo o que a sociedade burguesa constrói é construído para ser posto abaixo. 'Tudo o que é sólido' - das roupas sobre nossos corpos aos teares e fábricas que as tecem, aos homens e mulheres que operam as máquinas, às casas e aos bairros onde vivem os trabalhadores, às firmas e corporações que os exploram, às vilas e cidades, regiões inteiras e até mesmo as nações que as envolvem - tudo isso é feito para ser desfeito amanhã, despedaçado ou esfarrapado, pulverizado ou dissolvido, a fim de que possa ser reciclado ou substituído na semana seguinte e todo o processo possa seguir adiante, sempre adiante, talvez para sempre, sob formas cada vez mais lucrativas. 


\section{A OBSOLESCÊNCIA NA PRODUÇÃO DE MERCADORIAS: UM IMPERATIVO MATERIAL DO DESENVOLVIMENTO DO SISTEMA DO \\ CAPITAL}

Sob a lógica dessa perspectiva, afirmamos que a obsolescência se trata de um processo abrangente, ligado à necessidade de autorreprodução do capital a qual, portanto, afeta todos os elementos que este coloca em operação. Assim compreendendo, ratificamos nossa hipótese de que existe uma relação mais profunda entre a obsolescência e a natureza do capital. A seguir, apresentamos alguns aspectos desse processo.

\section{OBSOLESCÊNCIA PLANEJADA E A TAXA DE UTILIZAÇÃO DECRESCENTE DO VALOR-DE-USO}

$\mathrm{Na}$ perspectiva apresentada até agora, percebe-se uma correspondência entre a obsoletização das mercadorias e a forma de reprodução do capital através da extração da maisvalia relativa. Dessa relação é gerada uma incessante quantificação de mercadorias que, inevitavelmente, surge como um problema para o capital. Por isso, trataremos aqui do desenvolvimento da contradição produção/consumo, intentando mostrar a OP como específica de um momento histórico - o século XX. Porém, como decorrência de uma relação mais profunda, englobada na redução da taxa de uso dos produtos; processo este que, por sua vez, não se restringe a um único período histórico.

Ao nosso entender, a questão da OP está ligada ao modo como o capital efetiva sua reprodução historicamente. De fato, no capitalismo há um permanente esforço por alargar a estrutura do círculo de consumo com vistas a garantir mercados e a disseminar as práticas capitalistas devido à necessidade de rotação do capital. Outro esforço, por sua vez, trata de potencializar o giro da mercadoria na circulação de modo a sempre renovar a demanda por meio da obsoletização das mercadorias sem necessariamente alargar a estrutura do consumo o que o leva à busca pela manutenção ininterrupta da circulação. Porém, devido ao caráter ilimitado das necessidades do capital em relação às necessidades humanas, há sempre um desequilíbrio na relação oferta/demanda, o que provoca crises no seio do sistema. Consequência já prevista por Marx, quando este afirmava que

Ninguém pode vender sem que alguém compre. Mas ninguém é obrigado a comprar imediatamente, apenas por ter vendido. A circulação rompe com as limitações de tempo, de lugar e individuais, impostas pelas trocas de produtos, ao dissociar a identidade imediata que, nesta última, une a alienação do produto próprio e a aquisição do alheio, gerando a antítese entre venda e compra. [...] Se essa independência exterior dos dois atos - interiormente 


\section{A OBSOLESCÊNCIA NA PRODUÇÃO DE MERCADORIAS: UM IMPERATIVO MATERIAL DO DESENVOLVIMENTO DO SISTEMA DO \\ CAPITAL}

dependentes por serem complementares - prossegue se afirmando além de certo ponto, contra ela prevalece, brutalmente, a unidade, por meio de uma crise. (MARX, 2011a, p. 140).

Durante certo período do desenvolvimento capitalista, as contradições puderam ser deslocadas mediante a expansão das práticas produtivas. Contudo, a correspondência entre oferta e procura por meio da composição da demanda efetiva não se estabeleceu na prática, como explica Paniago (2012, p. 43), quando diz que "a capacidade de consumo dos capitalistas, a partir de uma certa escala, impõe limites humanamente intransponíveis e, por outro, que cada vez maior número de trabalhadores é eliminado do círculo de consumo". Assim, o capital deve buscar não somente a subordinação, mas, sobretudo, a eliminação prática da relevância do valor-de-uso, como forma de deslocar essa contradição, impondo a obsolescência das mercadorias, inclusive, como uma atividade planejada.

É nesse ínterim que surge a OP. A obsolescência de mercadorias como estratégia propositalmente planejada trata-se de um fenômeno observável a partir do final do primeiro quartel do século XX, quando se manifestou na indústria de lâmpadas elétricas que saiam das fábricas com um tempo de duração ou funcionamento preestabelecidov ${ }^{\mathrm{v}}$. Posteriormente, essa prática foi amplamente disseminada nos diversos ramos da produção industrial.

Packard (1965), em Estratégia do Desperdício, foi um dos primeiros autores a buscar sistematizar os modos da OP no campo industrial. Nesta obra, o autor estabelece três formas específicas de sua manifestação nos produtos nas décadas de 1950 e 1960 nos Estados Unidos, sendo estas: da função, da qualidade e da desejabilidade. O primeiro caso refere-se à substituição de um produto por outro que exerce a mesma função, porém, mediante uma inovação que provoca um melhoramento no que diz respeito a sua utilidade. O segundo, ocorre pelo esgotamento das possibilidades de uso em decorrência do desgaste, num tempo relativamente curto. No último caso, acontece quando nossa percepção, por motivos variados, é levada a conceber como obsoleto um determinado produto em relação a outro supostamente mais aprimorado.

Outros autores também teorizaram a respeito da OP. É o caso de Baran e Sweezy (1966), que entenderam esta prática como instrumento para se atender às exigências expansionistas do capitalismo monopolista do pós-guerra. De acordo com eles, com a superação da concorrência, foram desenvolvidos mecanismos cada vez mais eficazes de incentivo e dinamismo das vendas, uma vez que, no instável sistema de acumulação capitalista, "a competição dos preços 


\section{A OBSOLESCÊNCIA NA PRODUÇÃO DE MERCADORIAS: UM IMPERATIVO MATERIAL DO DESENVOLVIMENTO DO SISTEMA DO \\ CAPITAL}

desapareceu, em grande parte, como meio de atrair a preferência do público, dando lugar a novos modos de promoção de vendas: publicidade, variação do aspecto dos produtos, de sua embalagem, a 'Obsolescência Planejada.” (BARAN e SWEEZY,1966, p. 120). Pela ótica destes autores, estas modificações implicam na manutenção constante das taxas de produção e rotatividade do capital, uma vez que

[...] a obsolescência pré-fabricada aumenta a taxa de desgaste, e frequentemente, modificações de modelo aumentam a taxa de substituição. [...] O resultado líquido é uma intensificação na taxa de procura de reposição, e um surto geral na renda e no emprego. Sob esse aspecto, como em outros, as campanhas e vendas constituem um poderoso antídoto para a tendência do capitalismo monopolista de afundar-se num estado de depressão crônica. (BARAN e SWEEZY, 1966, pp. 135 - 136).

Mais recentemente, Harvey (2012, p. 129) chamou atenção para o fato de que a OP fez parte de uma série de medidas relacionadas à racionalização científica da administração da empresa capitalista durante a organização produtiva fordista. Uma tendência ao planejamento que, para ele, se manifesta em todas as instâncias da atividade corporativa, estando presente “[...] não somente [na] produção como também nas relações pessoais, treinamento no local de trabalho, marketing, criação de produtos, estratégias de preços, Obsolescência Planejada de equipamentos e produtos [...]". No entendimento deste autor, por conta da propensão do regime fordista à superprodução, houve a necessidade de controle econômico da flutuação da demanda efetiva - por isto, “a desvalorização através de violentas oscilações no ciclo econômico foi submetida ao controle e reduzida ao tipo de desvalorização equilibrada através da obsolescência planejada, que causava problemas relativamente pequenos." (HARVEY, 2012, p. 173). Ainda segundo Harvey, as estratégias de obsoletismo presentes no fordismo foram amplamente aplicadas em todos os setores da produção com a ascensão do sistema de "acumulação flexível”, no qual se acentuou a necessidade de diminuição da vida útil dos produtos em todos os ramos da produção. $\mathrm{O}$ autor afirma que

a meia vida de um produto fordista típico, por exemplo, era de cinco a sete anos, mas a acumulação flexível diminuiu isso em mais da metade em certos setores (como o têxtil e o do vestuário), enquanto em outros - tais como as chamadas indústrias de "thoughtware" (por exemplo, videogames e programas de computadores) - a meia vida está caindo para menos de dezoito anos. (HARVEY, 2012, p. 148). 


\section{A OBSOLESCÊNCIA NA PRODUÇÃO DE MERCADORIAS: UM IMPERATIVO MATERIAL DO DESENVOLVIMENTO DO SISTEMA DO \\ CAPITAL}

Situando a OP na esfera da produção, Mandel (1982, p. 161) relaciona a tendência de aceleração da produção capitalista ao fato de que as empresas do "capitalismo tardio" sejam marcadas pelo planejamento de suas atividades econômicas, o que inclui "dispêndios colossais em pesquisa, análise de mercado, publicidade e manipulação dos consumidores, obsolescência planejada de mercadorias $[\ldots . .]$.

Entendemos, por outro lado, que o aparecimento e o desenvolvimento da OP se correlacionam diretamente com o processo histórico que Mészáros identifica como sendo a taxa de utilização decrescente do valor-de-uso no capitalismo, ao afirmar que o capital segue a linha de menor resistência, ao invés de sofrer com as desconcertantes consequências da construção de uma estrutura para alargamento do círculo de consumo. A OP, desta forma, é parte componente do processo mais amplo da obsolescência de mercadorias, pois aparece no século XX, momento que, em linhas gerais, se afunila a contradição entre produção e consumo, o que pode ser comprovado através das recorrentes crises econômicas pelas quais passa o capitalismo no referido século.

Forjar mecanismos para aumentar a velocidade de rotação da mercadoria no circuito por meio da obsolescência faz parte da história do capitalismo que se manifesta pela indução da redução na taxa de utilização dos produtos na esfera do consumo. No caso da OP, esta surge no seio da empresa individual num momento de reorganização do processo de trabalho e de racionalização da produção, no qual o desenvolvimento da ciência e da tecnologia pôde proporcionar medidas de ação deliberada de controle sobre a demanda. Por isso, a OP forjada dentro da empresa capitalista representa uma atividade considerável do modus operandi do sistema e, possivelmente, sua tendência. Pela mediação da OP e de outros mecanismos, o que interessa ao capital é efetivar a aceleração do giro das mercadorias no vórtice da circulação. Para tanto, precisa introduzir a obsolescência - planejada deliberadamente - no interior das empresas ou apenas como efeito de uma necessidade de sobrevivência no mercado. Alcançar tal objetivo pela redução da durabilidade e da qualidade dos produtos pela inovação, pela manipulação deliberada dos consumidores através da propagada ou pela produção de armamentos através do fomento a necessidades fictícias tendo o Estado como aliado, é questão totalmente indiferente do ponto de vista daquilo que realmente importa para o capital - que é a realização da mais-valia por meio da venda de mercadorias. De acordo com Mészáros (2011, p. 660), essa realidade foi possível diante da 


\section{A OBSOLESCÊNCIA NA PRODUÇÃO DE MERCADORIAS: UM IMPERATIVO MATERIAL DO DESENVOLVIMENTO DO SISTEMA DO \\ CAPITAL}

[...] inovação baseada na percepção prática de que qualquer mercadoria, num extremo da escala, pode estar constantemente em uso ou, no outro extremo das possíveis taxas de utilização, absolutamente nunca ser usada, sem perder com isso sua utilidade no que se refere às exigências expansionistas do modo de produção capitalista.

Pois que

[...] uma certa quantidade de valor de troca foi realizada na mercadoria em questão através do próprio ato de venda independentemente de ser ela, na sequência, sujeita a uso constante, a pouco ou a nenhum uso (por exemplo a câmera fotográfica, que posso usar apenas uma vez por ano, nas férias, se tanto), conforme o caso. O capital define "útil" e "utilidade" em termos de vendabilidade: um imperativo que pode ser realizado sob a hegemonia e no domínio do próprio valor de troca. [...] De fato, enquanto a demanda efetiva do mesmo tipo de utilização é reproduzida com sucesso, quanto menos uma dada mercadoria é realmente usada e reusada (em vez de rapidamente consumida, o que é perfeitamente aceitável para o sistema), melhor é do ponto de vista do capital: já que tal subutilização torna vendável outra peça de mercadoria. (MÉSZÁROS, 2011, p. 660 - 661).

Fato é que, em tempos de crise estrutural do capital, a tendência histórica de decréscimo na taxa de utilização dos produtos transforma a obsolescência em uma atividade cada vez mais planejada e racional, o que a leva a extrapolar os limites da empresa individual, transformandoa em um fenômeno de alcance geral. Isso porque a ciência como uma atividade separada na divisão social do trabalho torna-se força produtiva capaz de promover a OP em larga escala. O resultado é sua aplicação à produção na qual se forja a tecnologia, um dos elementos responsáveis pela criação e recriação das necessidades individuais e sociais. Seus avanços logram para o sistema novas mercadorias, como também permitem ao capital uma maior eficiência na infusão no mercado de objetos que devem ter sua taxa de utilização reduzida. Diz Mészáros (2011, p. 660):

O fato de que os meios de produção se convertem em capital e como tal devem ser valorizados em uma escala sempre crescente, acarreta o desenvolvimento da tecnologia como uma prática produtiva paradoxalmente auto-orientada. [...] Como resultado, a tecnologia pode avançar na realização de seus objetivos autoimpostos, independentemente das implicações negativas de tal orientação autónoma, tanto em relação à taxa de utilização decrescente - manifestada, por um lado, na superprodução em massa de mercadorias e, por outro, no excesso acumulado de capacidade produtiva - como em relação ao seu impacto sobre o trabalho vivo. 


\section{A OBSOLESCÊNCIA NA PRODUÇÃO DE MERCADORIAS: UM IMPERATIVO MATERIAL DO DESENVOLVIMENTO DO SISTEMA DO \\ CAPITAL}

A consequência disso é que o capital adota formas de desperdício, bem como destruição de riquezas e de recursos diante do imperativo da obsolescência de mercadorias, eliminando do jogo o consumo real de valores-de-uso. É nesse sentido que Mészáros entende prevalecer, na prática, o consumo destrutivo em detrimento do consumo produtivo. E, ao nosso entender, é essa propensão a destrutividade e ao desperdício que torna a OP uma tendência às alternativas do capital na determinação das práticas produtivas no nosso tempo.

\section{CONSIDERA ÇÕES FINAIS}

Partimos nesse artigo do pressuposto que a obsolescência se configura como desdobramento do desenvolvimento histórico do capitalismo, buscando relacionar sua origem ao processo de subordinação do valor-de-uso ao valor-de-troca, pois, com a retirada do trabalhador do controle da demanda, o capital passou a determinar a quantidade e o modo de se consumir. O desenvolvimento das forças produtivas, por sua vez, expandiu o círculo de consumo, com o aparecimento de novas necessidades, deixando evidenciado a destruição criadora (obsolescência de mercadorias) como uma utilidade para o capital.

Esse percurso, acreditamos, permitiu a constatação de que a contradição entre produção e consumo (que impele o capital pela busca da quantificação e obsolescência) acompanha o capitalismo em sua história. Permitiu também compreender que a OP do século XX surge com o afunilamento dessa contradição em meio à evolução da ciência e da tecnologia. Por via desse raciocínio, indicamos que a OP se trata de um fenômeno atrelado ao processo histórico tendencial de diminuição da taxa de utilização do valor-de-uso, caracterizado pela indução da subutilização dos produtos pelos consumidores. O que pôde, por sua vez, viabilizar a interpretação de que as práticas produtivas capitalistas estão voltadas para a destruição e desperdício.

Assim, pensamos ter contribuído, por mediação da análise da obsolescência, com o debate acerca da importante questão da viabilidade deste sistema para uma reprodução social sustentável da humanidade. Sobretudo no que diz respeito ao caráter negativo desta em relação à luta de classes, na medida que a classe trabalhadora assume na prática (e ideologicamente) o consumismo (necessário ao capital do nosso tempo) como modelo de vida em contraposição a uma intervenção consciente no modo de reprodução. 


\section{A OBSOLESCÊNCIA NA PRODUÇÃO DE MERCADORIAS: UM IMPERATIVO MATERIAL DO DESENVOLVIMENTO DO SISTEMA DO \\ CAPITAL}

\section{REFERÊNCIAS}

BARAN, Paul e SWEEZY, Paul. Capitalismo monopolista. Rio de Janeiro: Zahar, 1966.

BERMAN, Marshall. Tudo que é sólido se desmancha no ar: a aventura da modernidade. São Paulo: Companhia das Letras, 1986.

Comprar, tirar, comprar: la historia secreta de la obsolescencia programada. Direção: Cosima Dannoritzer. Produção: Davina Breillet. Cooprodução: Espanha-França: Arte France, Televisión Española y Televisión de Catalunya. 2010. Documentário. (52 min). Disponível em: <https://www.youtube.com/warch?v=24CM4gV6w8>. Acesso em 05 dez. 2017.

HARVEY, David. Condição pós-moderna: uma pesquisa sobre as origens da mudança cultural. São Paulo: Edições Loyola, 2012.

MANDEL, Ernest. O capitalismo tardio. Coleção Os Economistas. São Paulo: Abril Cultural, 1982.

MARX, Karl. Grundrisse: manuscritos econômicos de 1857-1858: esboço da crítica da economia política. São Paulo: Boitempo Editorial, 2011.

O capital: crítica da economia política. Vol. 1, Livro I. Rio de janeiro: Civilização Brasileira, 2011a.

MARX, Karl \& ENGELS, Friedrich. Manifesto comunista. São Paulo: Boitempo Editorial, 2010.

MÉSZÁROS, István. O poder da ideologia. São Paulo: Boitempo Editorial, 2004.

Para além do capital. São Paulo: Boitempo Editorial, 2011.

PACKARD, Vance. Estratégia do desperdício. São Paulo: Ibrasa, 1965.

PANIAGO, Maria Cristina Soares. Mészáros e a incontrolabilidade do capital. $2^{a}$ ed. São Paulo: Instituto Lukács, 2012.

ROSDOLSKY, Roman. Gênese e estrutura de O capital de Karl Marx. Rio de Janeiro: EDUERJ: Contraponto, 2011.

SCHUMPETER, Joseph Alois. Capitalismo, socialismo e democracia. Rio de Janeiro: Editora Fundo de Cultura, 1961. 


\section{A OBSOLESCÊNCIA NA PRODUÇÃO DE MERCADORIAS: UM IMPERATIVO MATERIAL DO DESENVOL VIMENTO DO SISTEMA DO \\ CAPITAL}

\section{NOTAS}

iIstván Mészáros (2004) demonstra como Jonh Maynard Keynes exerceu, na primeira metade do século XX, forte influência ideológica ao afirmar que problemas (essencialmente socioeconômicos) seriam resolvidos por meio da mera aplicação da ciência e da eficiência técnica, depositando confiança cega num suposto avanço técnicomaterial. De acordo com Mészaros, Keynes intencionava justificar a produção de mercadorias à "acumulação de riquezas", que até hoje não resolveu o problema, nos levando a todo tipo de desperdício através da generalização da obsolescência. Por outro lado, essa perspectiva da OP como um método de equilibrar as oscilações do mercado, negligenciando o seu impacto na utilização dos recursos naturais, existe porque a base teórica de tais ideais parte de uma concepção de práticas produtivas orientadas para o valor-de-troca e não para o valor-de-uso.

iiBaseamo-nos aqui em Marx (2011), cuja leitura está restrita ao Livro I de "O Capital", além do Capítulo 14 de "Para Além do Capital" de István Mészáros. O objetivo consiste em apresentar os fatos e acontecimentos históricos condicionantes do desenvolvimento capitalista, notadamente aqueles relacionados à disjunção entre necessidade e produção, sem a qual não seria possível tal desenvolvimento, tampouco a obsolescência de mercadorias que lhe assegura.

iii Em sociedades de classe, onde prevalecem a exploração do homem pelo homem, a existência da produção de excedente é uma condição indispensável. De acordo com Rosdolsky (2011, p. 191 - 192), “Assim como os modos anteriores de exploração, também o modo dominado pelo capital se baseia no mais-trabalho do produtor direto. A relação capitalista, assim como a servidão ou a escravidão, não seria possível se o trabalho humano gerasse apenas o necessário para sustentar a vida dos produtores diretos. [...] qualquer exploração, qualquer dominação de classe, pressupõe condições naturais relativamente favoráveis a uma produtividade mínima do trabalho humano".

${ }^{i v}$ É possível que surjam controvérsias a respeito desta afirmação, de modo que é importante esclarecer que não estamos deduzindo a OP como já presente no início do desenvolvimento capitalista, mas tão-somente que existe uma obsolescência de mercadorias portadora de traços indicativos de práticas voltadas para o desperdício, contra a durabilidade, depreciação da qualidade etc., no momento em que falamos de diminuição tempo de vida útil.

"Informação do documentário "Comprar, tirar, comprar. La historia secreta de laobsolescencia programada". Ano 2010. Direção: Cosima Dannoritzer. Disponível em: http://www.rtve.es/alacarta/videos/eldocumental/documental-comprar-tirar-comprar/1382261/. Acessado em 11/11/2017. 